\title{
Mass Spectral Fragmentation Reactions of Angiotensin-Converting Enzyme (ACE) Inhibitors
}

\author{
David J. Burinsky and Scott L. Sides \\ Chemical Development Division, GlaxoSmithKline, Research Triangle Park, North Carolina, USA
}

\begin{abstract}
A variety of mass spectrometric techniques have been employed in the study of a series of structurally similar compounds used in the treatment of hypertension. The compounds, known collectively as angiotensin-converting enzyme (ACE) inhibitors, all share the amino acid residue proline or some variant thereof, as a common structural element. The gas phase fragmentation behavior of these compounds has been explored systematically using various instruments and techniques. An interesting dissociation process (rearrangement) unique to one of the compounds, lisinopril, has been investigated using isotopic labeling experiments and exact mass measurements. The general nature of the process has been probed through both the positive and negative ion analyses of fourteen related compounds exhibiting structural homology. (J Am Soc Mass Spectrom 2004, 15, 1300-1314) (C) 2004 American Society for Mass Spectrometry
\end{abstract}

$\mathrm{T}$ he metabolic transformations of various angiotensins in vivo constitute some of the most important biological processes involved in the disease state of hypertension (high blood pressure). The pivotal process in the angiotensin cascade is the cleavage of the decapeptide angiotensin I to produce the potent vasoconstrictor angiotensin II, an octapeptide. This hydrolytic elimination of the two-residue carboxylterminus dipeptide from angiotensin I is catalyzed by the angiotensin-converting enzyme (ACE), a zinc metallopeptidase [1]. Effective management of high blood pressure has been achieved over the past 20 years through the use of a class of orally active therapeutic agents that inhibit the production of angiotensin II by competitively binding to the active site of the ACE. Until recently, the structure of the ACE was unknown [2]. Previous supposition about the structure of the active binding site (by analogy to that of carboxypeptidase A [3]) led to the rational design of carboxyalkanoyl and mercaptoalkanoyl derivatives that mimic the dipeptide liberated from angiotensin I [4]. Many of the molecules in the class [5-7] contain the amino acid proline (or a proline-like surrogate), the carboxy group of which interacts with a positively charged atom or residue at the binding site. Two other structural elements thought to be necessary for effective competitive binding of inhibitor molecules are (1) an amide carbonyl oxygen (that hydrogen bonds with an acidic

Published online July 28, 2004

Address reprint requests to Dr. D. J. Burinsky, Chemical Development Division, GlaxoSmithKline, Five Moore Drive, P.O. Box 13398 Mail stop 2-4075-4A, Research Triangle Park, NC 27709-3398, USA E-mail: david.j. burinsky@gsk.com hydrogen at the binding site) and (2) a polarizable/ nucleophilic moiety (e.g., atoms such as sulfur, nitrogen, or phosphorous) to strongly coordinate with the zinc cation of the metalloenzyme.

Mass spectral analysis of therapeutic ACE inhibitors has largely focused on the detection and quantitation of these compounds in pharmaceutical preparations [8] or various biological matrices, in order to establish the pharmacokinetic and metabolic profiles of these agents [9-16]. Two publications have detailed the interactions of some of these molecules with metal ions, using mass spectrometry and ultraviolet spectroscopy to evaluate their potential role as radical scavengers [17, 18]. At least four compounds in this class have been the focus of studies where collision-induced dissociation and tandem mass spectrometry (MS/MS) have been used to probe their dissociation reactions $[19,20]$. Two of those compounds, lisinopril and zofenapril, exhibited interesting rearrangement reactions in the unimolecular dissociation chemistry of their protonated molecules $\left([\mathrm{M}+\mathrm{H}]^{+}\right)$under conditions of low-energy collisional activation.

In this paper we report a systematic comparison of the collision-induced fragmentation behavior for the molecular ions (both cations, $[\mathrm{M}+\mathrm{H}]^{+}$, and anions, $[\mathrm{M}$ $-\mathrm{H}]^{-}$) of fourteen compounds belonging to the ACE inhibitor class (Figure 1). The unimolecular gas-phase chemistry of the analytes was explored using several types of instruments to obtain generational relationships (from sequential dissociation and precursor ion experiments), elemental composition (from exact $\mathrm{m} / \mathrm{z}$ measurements), and the number of labile hydrogen atoms (through deuterium incorporation experiments). 

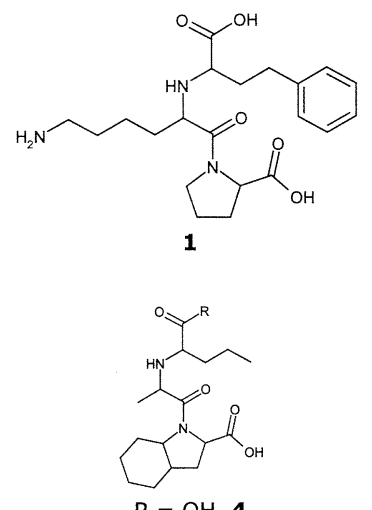

$\mathrm{R}=\mathrm{OC}_{2} \mathrm{H}_{5}, \mathbf{1 0}$

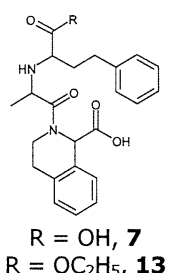

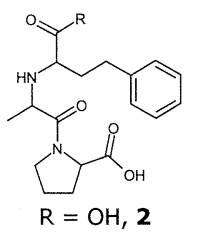

$\mathrm{R}=\mathrm{OC}_{2} \mathrm{H}_{5}, 9$

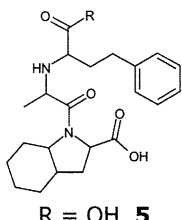

$\mathrm{R}=\mathrm{OC}_{2} \mathrm{H}_{5}, \mathbf{1 1}$
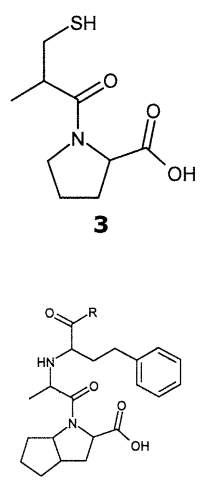

$\mathrm{R}=\mathrm{OH}_{,} 6$

$\mathrm{R}=\mathrm{OC}_{2} \mathrm{H}_{5}, 12$

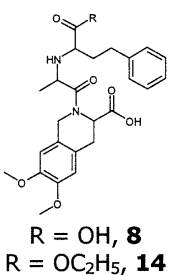

Figure 1. ACE inhibitor compounds 1-14.

The purpose of these experiments was to investigate the relationship between the structural homology responsible for biological activity and the gas-phase fragmentation behavior of these molecules, and thereby contribute additional insight into conclusions drawn from previous work about the dissociation chemistry of lisinopril. These results may also be useful in future fundamental or analytical studies of these compounds, being what may be the first report of the fragmentation behavior of the anions $\left([\mathrm{M}-\mathrm{H}]^{-}\right)$produced by deprotonation of the ACE inhibitors and their related compounds.

\section{Experimental}

\section{Mass Spectrometry}

Atmospheric pressure ionization (API) mass spectrometry experiments were performed using several instruments, including a ThermoFinnigan (San Jose, CA) TSQ7000 triple quadrupole mass spectrometer, a ThermoFinnigan LCQ quadrupole ion trap mass spectrometer, and a Waters/Micromass (Manchester, UK) QTOF2 quadrupole/time-of-flight mass spectrometer. The TSQ7000 and LCQ ITMS were equipped with the manufacturer's API2 atmospheric pressure ionization sources. APCI conditions (positive and negative) were as follows: heated vaporizer, $450{ }^{\circ} \mathrm{C}$; heated capillary, $250-300{ }^{\circ} \mathrm{C}$; discharge voltage, $4.5 \mathrm{kV}$; corona discharge current, $5 \mu \mathrm{A}$; HPLC eluent flow rate, $1 \mathrm{~mL}$ per min; nebulizing and auxiliary gas, nitrogen; nebulizing and auxiliary gas pressures, 80 and $20 \mathrm{psi}$, respectively. ESI conditions were as follows: heated capillary, 250$300{ }^{\circ} \mathrm{C}$; electrospray voltage, $5 \mathrm{kV}$; HPLC eluent flow rate, $1 \mathrm{~mL}$ per min; nebulizing and auxiliary gas, nitrogen; nebulizing and auxiliary gas pressures, 80 and 20 psi, respectively. Collision-induced dissociation (CID) experiments on the TSQ7000 were carried out at a measured pressure of 0.7 mTorr (multiple collision conditions, measured using a convectron gauge) using offset potentials of between 20 and $35 \mathrm{~V}$ (i.e., collision energies of $20-35 \mathrm{eV}$ in the laboratory frame of reference, $E_{\text {lab }}$ ) with xenon as collision gas. Product-ion spectra were acquired using either "unit" resolving power in the precursor ion selection stage (approximate peak width of $0.7 \mathrm{~m} / \mathrm{z}$ unit, full-width at half-maximum definition) or a resolving power for Q1 that passed several of the ions in the isotopic envelope into the collision region. This condition produces product-ion spectra that contain isotopic distribution information that is lost when precursor ions are isolated with unit resolving power. In the deuterium incorporation experiments, the Q1 resolving power was set at its typical value (passing ions of only a single $m / z$ value), avoiding potential interpretive ambiguities. Spectra were recorded using scan ranges suitable for the relative molecular mass $\left(\mathrm{M}_{\mathrm{r}}\right)$ of each particular analyte. Precursorion CID spectra were also acquired with unit resolving power settings for both Q1 and Q3 in order to explicitly define some of the familial relationships between the various dissociating ions. Scan rates for both mass spectra and product-ion spectra (MS/MS) typically were on the order of $1 \mathrm{~m} / \mathrm{z}$ unit per ms.

CID experiments on the LCQ ion trap mass spectrometer (ITMS) were conducted using the helium bath gas at the normal operating pressure of the instrument and an ion excitation energy (radial kinetic energy) of 
approximately 1-2 eV. Standard product-ion spectra were acquired with an isolation window setting that resulted in excitation of several of the species in the isotopic envelope of the precursor ion. As described above, this condition produces product-ion spectra that contain isotopic distribution information that is lost when precursor ions are isolated with unit resolution. However, for the deuterium incorporation experiments, the isolation window was narrowed so that only ions representing the ${ }^{12} \mathrm{C}$ isotopic $[\mathrm{M}+\mathrm{H}]{ }^{+}$signal were dissociated.

Exact mass measurements were made using a Waters/Micromass quadrupole time-of-flight (QTOF2) mass spectrometer. Ionization was affected using the manufacturer's Z-SPRAY source operating in the pneumatically assisted electrospray ionization mode. Electrospray ionization (ESI) conditions were as follows: source block temperature, $150{ }^{\circ} \mathrm{C}$; desolvation temperature, $300{ }^{\circ} \mathrm{C}$; capillary voltage, $3.0 \mathrm{kV}$; cone voltage, 30 $\mathrm{V}$; eluent flow rate, $2-10 \mu \mathrm{L}$ per min; collision gas, argon; collision energy $\left(\mathrm{E}_{\mathrm{lab}}\right), 20-30 \mathrm{eV}$. Beam transmittance was reduced approximately $50-70 \%$ by admittance of collision gas. Spectra were obtained with MS1 (Q1) set to transmit a monoisotopic precursor ion beam (i.e., unit mass resolving power) and the time-of-flight (TOF) mass analyzer set to acquire from $\mathrm{m} / \mathrm{z} 40$ to 600 . Spectra were acquired in continuum (profile) mode with a $1 \mathrm{~s}$ acquisition duration (summing of multiple scans) and a $0.1 \mathrm{~s}$ interacquisition delay. The pusher repetition rate was $30 \mathrm{kHz}$ and the sampling rate of the analyzer was $1 \mathrm{GHz}$ [21]. Single point lock mass correction was used for exact mass $(\mathrm{m} / \mathrm{z})$ determination, and the parent ion, $[\mathrm{M}+\mathrm{H}]^{+}$was utilized as the lock mass for product ion measurements. The measured resolving power was approximately 5200 (full-width at halfmaximum (FWHM) at $m / z 406$ ).

The samples were introduced into ESI sources using either a Harvard Apparatus (Holliston, MA) syringe pump or an Agilent (Palo Alto, CA) HPLC system. Sample solutions that accommodated direct infusion were introduced at flow rates on the order of 2-10 $\mu \mathrm{L}$ per min. When sample mixtures warranted chromatographic separation, compounds were eluted from a reverse-phase $C_{18}$ column (50 mm $\times 2 \mathrm{~mm}, 3 \mu$ particles, Phenomenex, Torrance, CA) operating at a flow rate of $0.7 \mathrm{~mL} / \mathrm{min}$. The flow rate of the effluent introduced into the ESI source of the QTOF2 instrument was $0.2 \mathrm{~mL} / \mathrm{min}$.

\section{Chemicals}

Compounds 3, 9-14 were obtained as commercially available products. Sample preparation involved dissolution of the dosage form (in water or 50:50 water/ acetonitrile) and filtration prior to injection onto the HPLC column. Compound $\mathbf{1}$ was obtained as drug substance, which was dissolved, filtered and infused directly. Sample solutions were prepared at an approximate concentration of $1 \mathrm{mg} / \mathrm{mL}$. Injection volumes

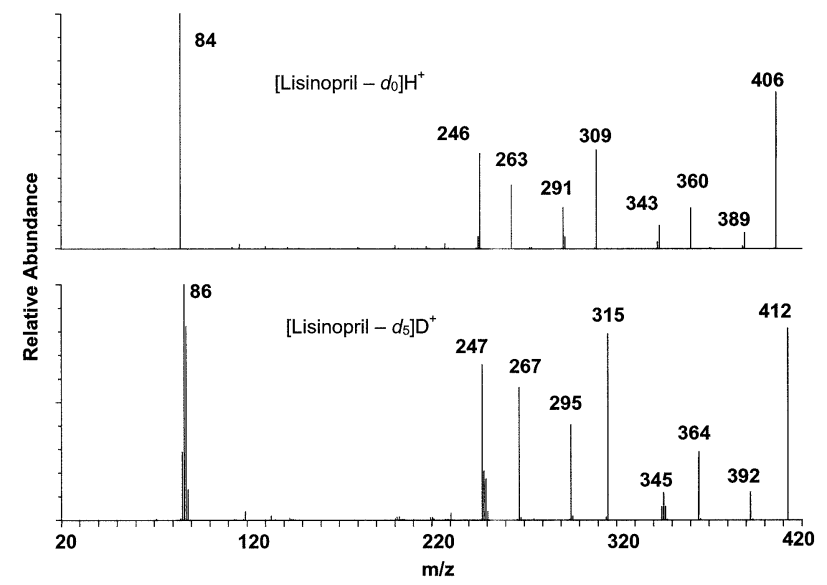

Figure 2. Product ion collision-induced dissociation (CID) MS/MS spectrum for the $\left[\mathrm{M}-d_{0}+\mathrm{H}\right]^{+}$ion $(m / z$ 406) (upper panel) and $\left[\mathrm{M}-d_{5}+\mathrm{D}\right]^{+}(\mathrm{m} / \mathrm{z} 412)$ (lower panel) of lisinopril.

were typically $1 \mu \mathrm{L}$. Compounds 2, 4-8 were prepared in situ by treating the sample solutions of the respective ethyl esters with $0.1 \mathrm{~N}$ aqueous $\mathrm{HCl}$. In general, a reaction time of approximately $24-48 \mathrm{~h}$ (ambient temperature) was sufficient to partially hydrolyze the ester, producing an acceptable quantity of the desired diacid compounds. The mobile phase for the standard positive and negative ion ESI experiments was comprised of water, acetonitrile and formic acid, in proportions suitable for some modest chromatographic retention, ranging from 75:25:0.05 ( $\mathrm{vol} / \mathrm{vol} / \mathrm{vol}$ ) to 95:5:0.05 ( $\mathrm{vol} / \mathrm{vol} /$ vol). The MilliQ water was replaced with $\mathrm{D}_{2} \mathrm{O}(99.9$ atom $\%$ D) for the deuterium exchange experiments. All solvents, gases and other reagents were obtained commercially and used as received-water (Millipore MilliQ UF purification system, Billerica, MA); acetonitrile and formic acid (EM Science, Hawthorne, NY); deuterium oxide (Aldrich Chemicals, Milwaukee, WI); hydrochloric acid (Mallinckrodt, Paris, KY).

\section{Results and Discussion}

\section{Positive Ion Study}

Investigation of the ACE inhibitors was undertaken after an unexpected rearrangement was observed for the protonated molecule $\left([\mathrm{M}+\mathrm{H}]^{+}\right)$of lisinopril, 1 . Such rearrangement processes are of interest from the perspective of fundamental gas-phase ion chemistry, as well as for the impact they have on the interpretation of collision-induced dissociation spectra in the context of characterization of unknown organic compounds. Florêncio and coworkers [19] reported the fragmentation behavior of lisinopril, 1, under low-energy collisioninduced dissociation conditions. Among the dissociation reactions exhibited by the $[\mathrm{M}+\mathrm{H}]^{+}$ion $(\mathrm{m} / z$ 406) of lisinopril (Figure 2), elimination of neutral $\mathrm{C}_{5} \mathrm{H}_{7} \mathrm{NO}$ $(\mathrm{m} / \mathrm{z} 309)$ was particularly interesting since it requires that a functional group migration/rearrangement must either precede or accompany the elimination of dihy- 


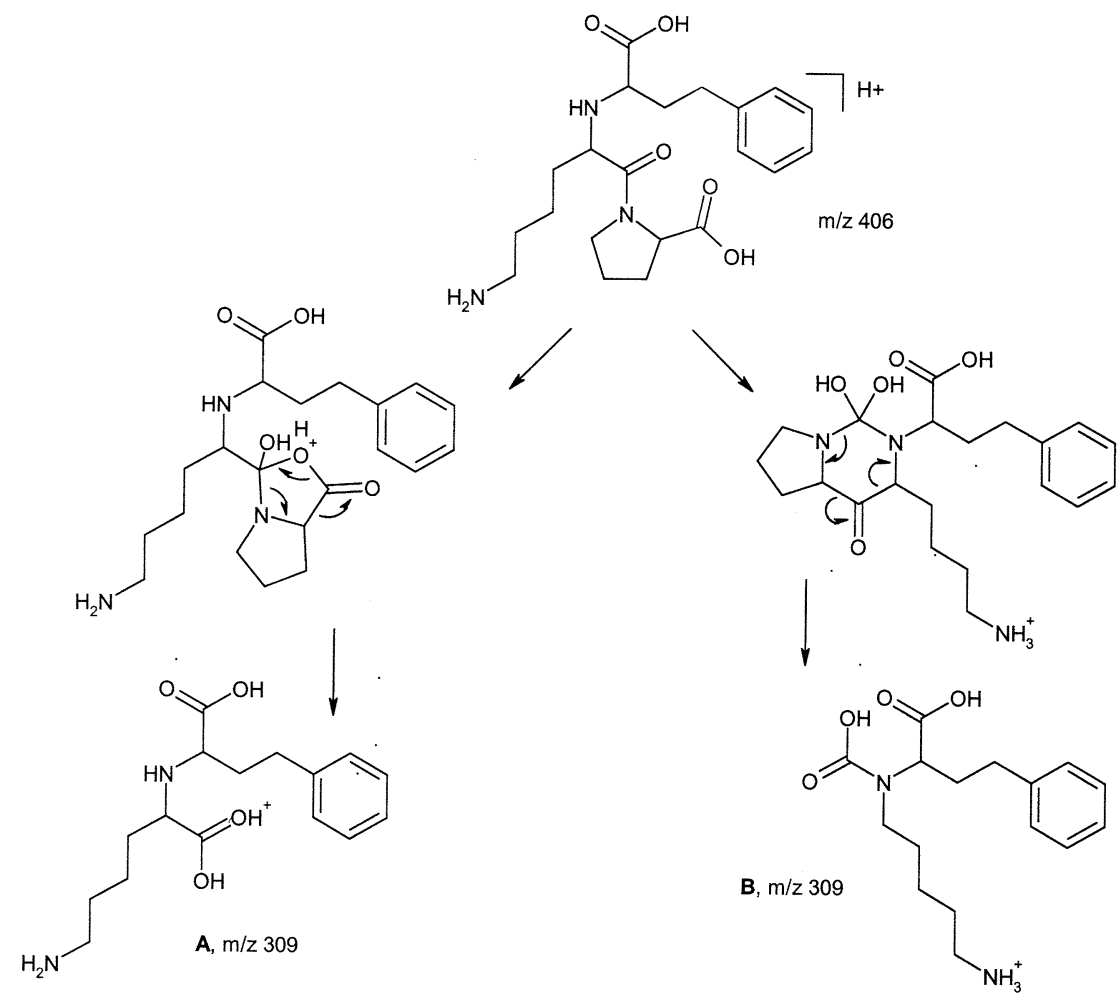

Scheme 1. Possible mechanisms for the rearrangement accompanying the elimination of $\mathrm{C}_{5} \mathrm{H}_{7} \mathrm{NO}$ from the $[\mathrm{M}+\mathrm{H}]^{+}$ion $(\mathrm{m} / \mathrm{z} 406)$ of lisinopril. The mechanism leading to Structure A was proposed in a previous study [19].

dropyrrole and carbon monoxide. Both exact mass $(\mathrm{m} / \mathrm{z})$ measurements and deuterium exchange experiments confirmed the elemental composition of the leaving neutrals. It cannot be established unequivocally from these data whether the elimination reaction produces two molecules (dihydropyrrole and $\mathrm{CO}$ ) or a single neutral molecule (dihydropyrrolecarbaldehyde). The measured mass-to-charge ratio of 309.1808 compared favorably with the calculated (expected) value of 309.1809 (accuracy $=-0.4 \mathrm{ppm}$; standard deviation $=$ $1.1 \mathrm{ppm})$. Replacement of the aqueous component of the HPLC eluent with $\mathrm{D}_{2} \mathrm{O}$ resulted in a complete exchange of all labile protons in the analyte molecule [22]. For lisinopril, the deuterium exchange experiment produced the expected mass shift of $6 \mathrm{Da}(\mathrm{m} / \mathrm{z} 406$, $\left[\mathrm{M}-d_{0}+\mathrm{H}\right]^{+}$to $\left.\mathrm{m} / \mathrm{z} 412,\left[\mathrm{M}-d_{5}+\mathrm{D}\right]^{+}\right)$. Collisional activation of the $412^{+}$ions produces product ions at $\mathrm{m} / \mathrm{z}$ 315 that contain all six of the incorporated deuterons, indicating no labile hydrogen atoms in the eliminated neutrals. The authors of the previous lisinopril study proposed a hydroxyl group transfer as the rearrangement process that accompanies (or precedes) the elimination of $\mathrm{C}_{5} \mathrm{H}_{7} \mathrm{NO}$. A transfer of the hydroxyl group from the proline carboxylic acid carbon atom to the carbonyl carbon atom of the lysine-proline amide bond requires a five-centered transition state (Structure A, Scheme 1). This process depends on protonation of the amide oxygen atom, followed by a concerted hydroxy group transfer to the amide carbonyl carbon with elimination of dihydropyrrole and carbon monoxide. Given the relative proton affinities of the three nitrogencontaining functional groups in the molecule (assumed to the most probable sites of protonation), it seemed improbable that a large enough portion of the $[\mathrm{M}+\mathrm{H}]^{+}$ ion population attained the necessary structure to initiate the fragmentation scheme leading to Structure A (Scheme 1). If however, the terminal lysine amine group was the predominate site of protonation, then some considerable degree of proton "mobility" would need to precede fragmentation in order to produce the requisite protonated amide ion structure. Any "interaction" or proton transfer between the lysine amine group and the amide group would require an unusual ninecentered transition state geometry. The respective proton affinities of these two functional groups also do not favor the aforementioned proton transfer. Another possible explanation for the interesting $\mathrm{C}_{5} \mathrm{H}_{7} \mathrm{NO}$ elimination would invoke a charge-remote mechanism. This mechanism depends neither on the initial location of the ionizing proton nor its mobility, in this case from a more basic functional group to a less basic functional group. An interesting aspect of the mechanism summarized in Scheme $\mathbf{1}$ (culminating in Structure B) is the transfer/rearrangement of the carboxylic acid group (i.e., electrophilic attack of a carboxylic acid carbonyl carbon on the lone pair electrons of a secondary nitro- 
gen atom through a six-centered transition state). Differentiation of isomeric ion structures, such as the two shown in Scheme 1, based on their CID product ion spectra depends on the presence of one or more signals that uniquely elucidates one of the putative structures. Unfortunately, isomeric ions are often not differentiable a priori, because many (if not all) of the dissociation products can be rationalized from any of the possible structures. Such is the case for the $m / z 309$ fragment in the CID product ion spectrum of lisinopril. Neither product ion spectra, deuterium exchange experiments, nor exact $m / z$ measurements can provide unequivocal evidence in favor of one of the possible structures, (A or B), over the other.

The CID spectra of the deuterated and non-deuterated lisinopril molecular ions also exhibit other interesting dissociation processes. The primary amino group on the lysine side-chain is the likely site of protonation leading to the elimination of ammonia $\left(406^{+} \rightarrow 389^{+}\right.$for lisinopril- $d_{0}$ and $412^{+} \rightarrow 392^{+}$for lisinopril- $\left.d_{5}\right)$. The $m / z$ 360 signal in the spectrum of protonated lisinopril- $d_{0}$ $\left(406^{+} \rightarrow 360^{+}\right)$presumably results from a competing reaction channel, loss of $\mathrm{HCO}_{2} \mathrm{H}$ in a single step process, or consecutive losses of water and $\mathrm{CO}$, although no signal is observed for the water loss product $\left(406^{+} \rightarrow\right.$ $\left.388^{+}\right)$. The analogous result $\left(412^{+} \rightarrow 364^{+}\right.$, loss of $\mathrm{DCO}_{2} \mathrm{D}$, or loss of $\mathrm{D}_{2} \mathrm{O}$ and $\mathrm{CO}$ ) was observed in the lisinopril- $d_{5}$ product ion spectrum. The appearance of this dissociation channel was unexpected considering the intrinsic basicity of the three nitrogen-containing functional groups in the molecule. The incorporation of two deuterons into the eliminated formic acid (or water) molecule requires that either a portion of the [M $+\mathrm{H} / \mathrm{Dl}^{+}$ion population is protonated/deuterated at one of the phenylbutyric acid oxygen atoms, or that the ionizing proton/deuteron is mobile enough [23] to migrate to the carboxylic acid group after collisional excitation but prior to fragmentation. The presence of two carboxylic acid groups in compounds 1, 2, 4-8 provides two possible sources for the lost formic acid molecule. Interestingly, the formic acid loss originates exclusively from the carboxylic acid group in the $\mathrm{N}$ terminus blocking group, as indicated by the corresponding loss of ethylformate from the ethyl ester compounds, 9-14. There is no signal corresponding to the loss of formic acid in the product ion spectra of those compounds. The aforementioned competitive processes $\left(-\mathrm{NH}_{3}\right.$ and $\left.-\mathrm{HCO}_{2} \mathrm{H}\right)$ combine in a consecutive (or concerted) fashion (either $406^{+}-\mathrm{NH}_{3}-$ $\mathrm{HCO}_{2} \mathrm{H}$ or $406^{+}-\mathrm{HCO}_{2} \mathrm{H}-\mathrm{NH}_{3}$ ) to generate the product ion at $m / z 343$. Sequential dissociation experiments (so called MS/MS/MS or $\mathrm{MS}^{3}$ ) conducted using both ion trap and QTOF mass spectrometers (shown in Table 1) confirm that both channels are operative, although the relative abundance of the $\mathrm{m} / \mathrm{z} 343$ ion signal is greater in the $\mathrm{MS}^{3}$ spectrum of $360^{+}$(i.e., $406^{+}$ $\rightarrow 360^{+} \rightarrow$ fragments, $100 \%$ relative abundance in the ITMS spectrum and $30 \%$ relative abundance in the QTOF spectrum) than in that of $389^{+}$(i.e., $406^{+} \rightarrow 389^{+}$ $\rightarrow$ fragments, $8 \%$ relative abundance in the ITMS spectrum and 3\% relative abundance in the QTOF spectrum). Since the ionizing deuteron can only be lost with one of the two neutral molecules eliminated during the consecutive dissociation processes, one of the elimination reactions must be charge-remote in nature, not relying on the ionizing proton. This fact is confirmed by the deuterium exchange product ion spectrum, which exhibits a signal at $m / z 345\left(412^{+}-\mathrm{ND}_{3}-\mathrm{HCO}_{2} \mathrm{D}\right.$ or $\left.412^{+}-\mathrm{DCO}_{2} \mathrm{D}-\mathrm{ND}_{2} \mathrm{H}\right)$. Close examination of the $345^{+}$isotopic distribution reveals some appreciable signal intensity at the adjacent $\mathrm{m} / \mathrm{z}$ values of 344 and 346. The appearance of these signals depends upon considerable mobility of the exchangeable deuterons. One case requires that both reactions are charge-remote (not involving the ionizing deuteron) resulting in the loss of $\mathrm{HCO}_{2} \mathrm{D}$ and $\mathrm{ND}_{2} \mathrm{H}$ and producing a signal at $m / z$ 346. The second case depends upon participation of an exchangeable deuteron from one of the other functional groups, explaining the signal at $m / z 344$ (due to the consecutive losses of $\mathrm{DCO}_{2} \mathrm{D}$ and $\mathrm{ND}_{3}$ ).

The most diagnostic fragmentation process for peptide and protein ions is cleavage of the amide bond. This process produces the well-known $\mathrm{N}$ terminal $b \quad\left(\left[\mathrm{H}_{2} \mathrm{NCH}(\mathrm{R}) \mathrm{CO}\right]^{+}\right)$and C-terminal $y^{\prime \prime}$ $\left({ }^{+}\left[\mathrm{H}_{3} \mathrm{NCH}(\mathrm{R}) \mathrm{CO}_{2} \mathrm{H}\right]\right)$ ions [24] that provide the blueprint for primary amino acid sequence determinations by mass spectrometry. Although only dipeptides, all of the ACE inhibitor compounds in this study (with the exception of captopril) have the potential for exhibiting one or both of the characteristic peptide cleavage ions. Protonated lisinopril displays the $b$ ion signal in its CID product ion spectrum $\left(\mathrm{m} / \mathrm{z} 291\right.$ for lisinopril- $d_{0}$ and $m / z$ 295 for lisinopril- $\left.d_{5}\right)$, with no evidence of the complimentary $y^{\prime \prime}$ ion signal $(m / z \quad 116)$. The peptide bond cleavage occurs primarily from the intact protonated molecule $\left([\mathrm{M}+\mathrm{H}]^{+}\right)$, since the $291^{+}$ion appears in only one (and at low abundance) of the $\mathrm{MS}^{3}$ spectra summarized in Table 1. A related fragmentation reaction for peptide ions is $a$ ion $\left(\left[\mathrm{H}_{2} \mathrm{NCH}(\mathrm{R})\right]^{+}\right)$formation. This fragment ion forms either by direct cleavage of the peptide backbone between the $\alpha$-carbon and the amide carbonyl carbon, or through a series of two consecutive cleavages, with $b$ ion formation followed by elimination of carbon monoxide. The $263^{+}$product ion in the protonated lisinopril MS/MS spectrum is just such an $a$ ion, as verified by the analogous $m / z 267$ in the deuterium exchange product ion spectrum (Figure 2, lower panel). The first of the two remaining significant signals in the product ion spectrum of the protonated lisinopril molecule is $m / z$ 246. This ion results from several consecutive dissociation processes involving the proline residue ( $b$-ion formation), the carbonyl group adjacent to the proline residue ( $a$-ion formation), and the terminal amino group of the lysine side chain $\left(406^{+} \rightarrow 389^{+}\right.$ $\rightarrow 274^{+} \rightarrow 246^{+}$or $406^{+} \rightarrow 291^{+} \rightarrow 263^{+} \rightarrow 246^{+}$). The isotopic distribution of the deuterium labeled dissociation product signal at $\mathrm{m} / \mathrm{z} 247$ indicates some scrambling or mobility of the deuterons. As shown in Scheme 
Table 1. Summary of the sequential fragmentation spectra $\left(\mathrm{MS}^{3}\right)$ of the major ions observed in the product ion MS/MS spectrum of protonated lisinopril $\left([\mathrm{M}+\mathrm{H}]^{+}\right)$. Spectra were acquired on both quadrupole ion trap (ITMS) and quadrupole/time-of-flight (QTOF) mass spectrometers

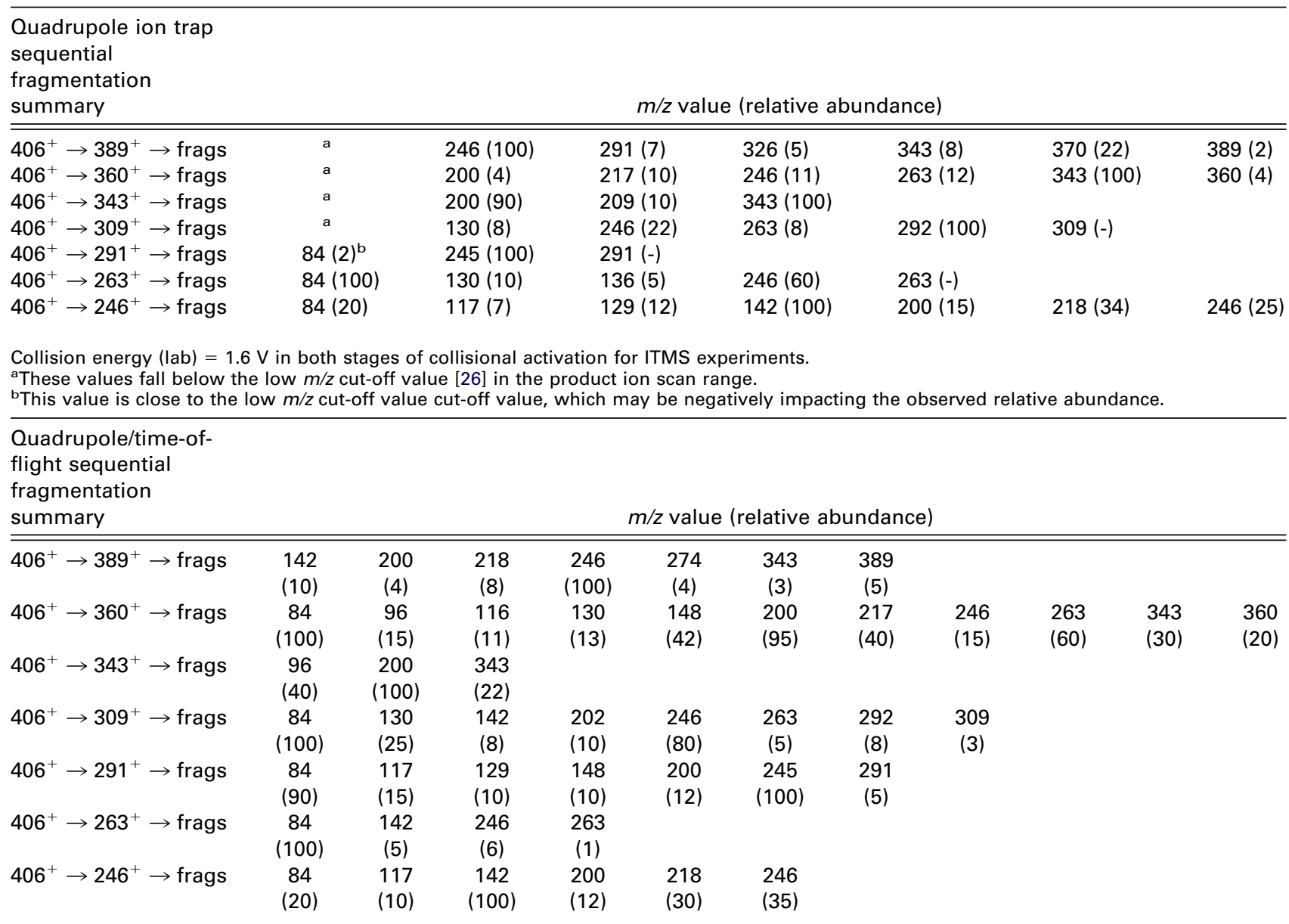

Collision energy $(\mathrm{lab})=22 \mathrm{~V}$; cone voltage $=40 \mathrm{~V}$.

Note: there is no mass selection prior to the first stage of collisional activation (i.e., skimmer cone collisional activation).

2, the $\mathrm{m} / \mathrm{z} 248$ ion is the expected product of the dissociation of the fully deuterated $412^{+}$precursor ion. The greater abundance of the $m / z 247$ ion indicates that a fifth deuteron is transferred from one of the other functional groups. The other signal of significant intensity in the isotopic distribution $(\mathrm{m} / \mathrm{z} 249)$ represents the elimination of neutrals that are deficient in deuterons, possessing only three. Two of these three processes reveal unanticipated mobility of deuterons and other hydrogen atoms in the precursor ion structure, presumably as a consequence of collisional activation. In one case, more than the predicted number of deuterons is lost and in the other case, fewer than the predicted number of deuterons is lost. In either case, one of the dissociation reactions occurs in the absence of the ionizing deuteron (i.e., charge remote). The neutrals containing fewer that the expected number of deuterons result from an intramolecular back exchange reaction. This outcome reflects the replacement of a deuteron in either the lysine side chain $-\mathrm{ND}_{2}$ or the carboxylic acid -OD with a "non-exchangeable" hydrogen atom from elsewhere within the ion.
Perhaps the most interesting signal in the CID product ion spectrum of the protonated lisinopril molecule is the base peak at $\mathrm{m} / \mathrm{z} 84$. This ion also produces a dominant signal in the $\mathrm{MS}^{3}$ spectra of five of the seven significant product ions of lisinopril. In particular, the presence of this ion in the $\mathrm{MS}^{3}$ spectrum of the $246^{+}$ion $\left(406^{+} \rightarrow 246^{+} \rightarrow 84^{+}\right)$supports a tetrahydropyridine structure, although other isomeric structures cannot be ruled out. The complexity of the processes responsible for the formation of the $\mathrm{m} / \mathrm{z} 84$ product ion is revealed upon examination of the CID product ion spectrum of [lisinopril- $d_{5}$ ] $\mathrm{D}^{+}, m / z 412$. The signal displays a surprisingly complex isotopic distribution, showing significant signal intensity at $\mathrm{m} / \mathrm{z} 85 \quad\left(\mathrm{C}_{5} \mathrm{H}_{9} \mathrm{DN}^{+}\right), \mathrm{m} / \mathrm{z} \quad 86$ $\left(\mathrm{C}_{5} \mathrm{H}_{8} \mathrm{D}_{2} \mathrm{~N}^{+}\right), \quad \mathrm{m} / \mathrm{z} \quad 87 \quad\left(\mathrm{C}_{5} \mathrm{H}_{7} \mathrm{D}_{3} \mathrm{~N}^{+}\right)$, and $\mathrm{m} / \mathrm{z} 88$ $\left(\mathrm{C}_{5} \mathrm{H}_{6} \mathrm{D}_{4} \mathrm{~N}^{+}\right)$with relative abundances of $30,100,80$, and $15 \%$, respectively (see Figure 2, lower panel). The variety of species revealed by the labeling experiment indicates multiple reaction pathways and multiple precursor ions of different structure or sites of protonation. The higher mass isotopomers at $\mathrm{m} / \mathrm{z} 87$ and 88 are particularly interesting. The incorporation of three or 

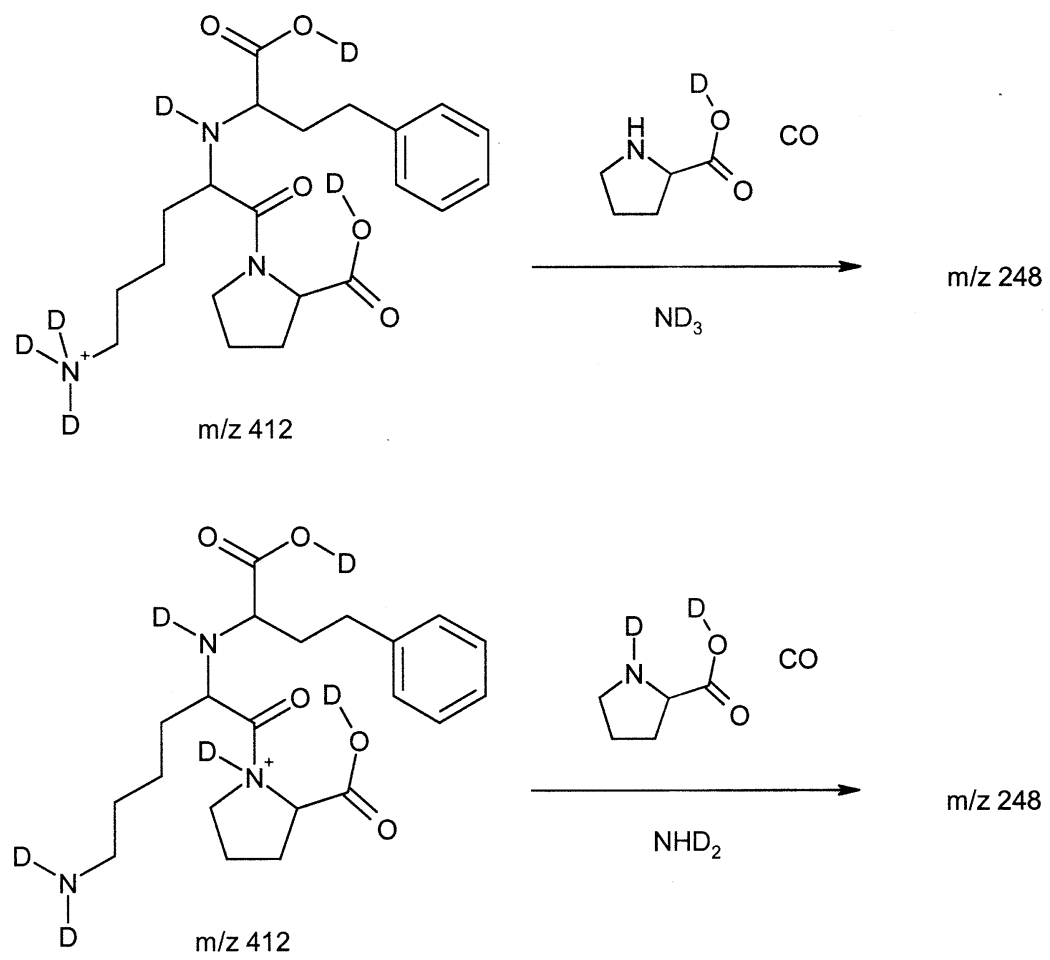

Scheme 2. Proposed mechanisms for the elimination of deuterium-labeled neutrals from the $\mathrm{m} / \mathrm{z} 248$ dissociation product of labeled lisinopril, $m / z 412$, $\left[\mathrm{M}-d_{5}+\mathrm{D}\right]^{+}$.

four deuterons requires either a linear protonated dieneamine structure for the $87^{+}$ion, or incorporation of deuterons into the alkyl portion of the lysine side chain, replacing non-labile (i.e., "non-exchangeable") carbonbonded hydrogen atoms, in the case of the $88^{+}$ion (see Figure 2). This high degree of isotopic scrambling is indicative of considerable mobility among the deuterons and is a reflection of the relatively long time required for the formation of the $\mathrm{m} / \mathrm{z} 84$ ion.

The previous fragmentation study of lisinopril noted the significant abundance of the $\mathrm{m} / \mathrm{z} 246$ signal in the ESI mass spectrum obtained at high values of cone voltage (one of the characteristic experimental parameters for the particular instrument on which the experiments were conducted). This observation prompted the investigators to probe its structure in a sequential CID experiment. Rationalization of the ensuing product ion structures $(\mathrm{m} / \mathrm{z} 218,200$, and 142$)$ led to a proposal for the structure of the $246^{+}$ion that required an unusual carbon-carbon bond scission of the butylamine side chain of the lysine residue, elimination of ethylamine (Scheme 3). The structure of $246^{+}\left(\mathrm{C}_{14} \mathrm{H}_{16} \mathrm{NO}_{3}^{+}\right)$reported by Florêncio et al. requires the elimination of proline $\left(\mathrm{C}_{5} \mathrm{H}_{9} \mathrm{NO}_{2}\right)$ and ethylamine $\left(\mathrm{C}_{2} \mathrm{H}_{7} \mathrm{~N}\right)$. The calculated $\mathrm{m} / z$ value for $\mathrm{C}_{14} \mathrm{H}_{16} \mathrm{NO}_{3}^{+}$is 246.1125 , while the measured $\mathrm{m} / \mathrm{z}$ value for the observed lisinopril product ion was determined to be 246.1495 . These two values differ by approximately $135 \mathrm{ppm}$, indicating a low probability that the $246^{+}$ion has the empirical formula (and structure) proposed in the previous lisinopril study. If instead of proline and ethylamine, protonated lisinopril produces $\mathrm{m} / \mathrm{z} 246$ product ions through the consecutive losses of ammonia, proline and carbon monoxide, the resulting ion would have an empirical formula of $\mathrm{C}_{15} \mathrm{H}_{20} \mathrm{NO}_{2}^{+}$, with a calculated $\mathrm{m} / z$ value of 246.1489. The agreement of the measured and calculated values (accuracy $=2.4 \mathrm{ppm}$; standard deviation $=$ $1.0 \mathrm{ppm})$, supports the proposed fragmentation pathway. The major dissociation products of $\mathrm{m} / \mathrm{z} 246$ result from elimination of styrene, producing the product ion at $\mathrm{m} / \mathrm{z} 142\left(\mathrm{C}_{15} \mathrm{H}_{20} \mathrm{NO}_{2}^{+}\right.$, calculated $\mathrm{m} / \mathrm{z}=142.0845$, measured $\mathrm{m} / \mathrm{z}=142.0851$, accuracy $=2.8 \mathrm{ppm}$; standard deviation $=6.7 \mathrm{ppm}$ ), and the sequential losses of $\mathrm{CO}$, producing the product ion at $\mathrm{m} / z 218\left(\mathrm{C}_{14} \mathrm{H}_{20} \mathrm{NO}^{+}\right.$, calculated $\mathrm{m} / \mathrm{z}=218.1545$, measured $\mathrm{m} / \mathrm{z}=218.1536$, accuracy $=4.1 \mathrm{ppm}$; standard deviation $=5.3 \mathrm{ppm}$ ), and $\mathrm{H}_{2} \mathrm{O}$, producing the product ion at $\mathrm{m} / \mathrm{z} 200$ $\left(\mathrm{C}_{14} \mathrm{H}_{18} \mathrm{~N}^{+}\right.$, calculated $\mathrm{m} / \mathrm{z}=200.1495$, measured $\mathrm{m} / \mathrm{z}=$ 200.1434 , accuracy $=30.5 \mathrm{ppm}$; standard deviation $=$ $16.8 \mathrm{ppm}$ ). The product ion at $\mathrm{m} / \mathrm{z} 200$ could also result from a competing concerted process (loss of formic acid, $\left.\mathrm{HCO}_{2} \mathrm{H}\right)$ that cannot be ruled out as the source of a portion of the $200^{+}$ion population. It seems likely that the original proposal of a ketene structure for the $\mathrm{m} / \mathrm{z}$ 246 ion was due in part to the facility with which such an ion might eliminate $\mathrm{CO}$, producing the subsequent product ion at $\mathrm{m} / \mathrm{z} 218$. Once the ketene structure is ruled out on the basis of exact $m / z$ measurements, the only plausible mechanism for decarbonylation requires a hydroxyl group transfer. This event would represent the second occurrence of an intramolecular rearrangement occurring in the dissociation cascade of proton- 


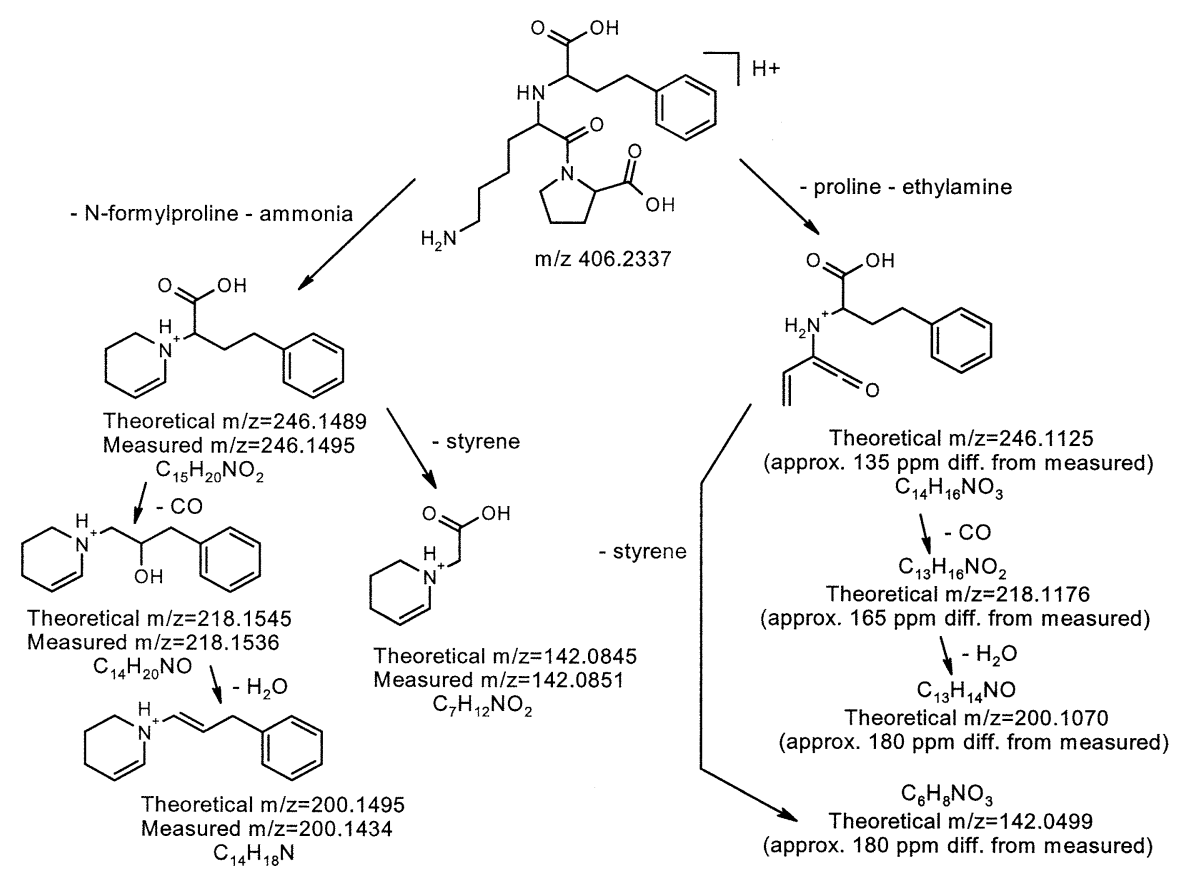

Scheme 3. Comparison of dissociation pathways for the $m / z 246$ ion obtained via sequential steps of collisional activation from protonated lisinopril. Proposed structures are based on exact $\mathrm{m} / \mathrm{z}$ measurements obtained in the present study (left side), and reported in a previous study (right side).

ated lisinopril (vide supra formation of $m / z 309$ from [M $\left.+\mathrm{H}^{+}\right)$.

The CID product ion spectra of both [lisinopril- $\left.d_{0}\right] \mathrm{H}^{+}$ and [lisinopril- $\left.d_{5}\right] \mathrm{D}^{+}$revealed evidence of considerable mobility amongst the labile hydrogens/deuterons, particularly the ionizing $\mathrm{H}^{+} / \mathrm{D}^{+}$. To gain some additional insight into the unimolecular dissociation processes, the sodium ion attachment products (i.e., [lisinopril$\left.d_{0}\right] \mathrm{Na}^{+}, m / z 428$ and [lisinopril- $\left.d_{5}\right] \mathrm{Na}^{+}, m / z$ 433) were subjected to the same collisional activation conditions used to interrogate the protonated/deuterated molecules. The highest mass dissociation product observed $(\mathrm{m} / \mathrm{z} 331 / 336)$ results from the elimination of $\mathrm{C}_{5} \mathrm{H}_{7} \mathrm{NO}$, indicating that the mechanism responsible for the functional group transfer reaction of $-\mathrm{OH}$ (or possibly $-\mathrm{CO}_{2} \mathrm{H}$ ) remained operative in the absence of an ionizing proton/deuteron. Notably absent from the spectra of the sodiated ions are the three highest mass product ions, corresponding to the competitive and consecutive losses of $\mathrm{NH}_{3}$ and $\mathrm{HCO}_{2} \mathrm{H}(\mathrm{m} / \mathrm{z} 389,360$, and 343, Figure 2). The scission of the amide bond is responsible for the next signal $(\mathrm{m} / \mathrm{z} 313 / 316)$ in the product ion spectrum, through elimination of neutral proline $\left(\mathrm{C}_{5} \mathrm{H}_{9} \mathrm{NO}_{2} /\right.$ $\mathrm{C}_{5} \mathrm{H}_{7} \mathrm{D}_{2} \mathrm{NO}_{2}$ ). Although this ion nominally corresponds to the $b$-ion of the protonated lisinopril molecule, there appear to be several interesting differences. The elimination of proline- $d_{2}$ from the [lisinopril- $\left.d_{5}\right] \mathrm{Na}^{+}$ion indicates mobility among the labile deuterons, with one of the other exchanged deuterons being transferred to (and eliminated with) the proline nitrogen atom. Subsequent loss of CO from the $b$ ion $\left(313^{+} \rightarrow 285^{+}\right)$ produces the peptide $a$ ion, a dissociation channel that is observed for both protonated and sodiated lisinopril species. Thus far, all of the reaction channels observed in the product ion spectrum of sodiated lisinopril corresponded to analogous processes of the protonated species. The first deviation from that similarity of behavior was exemplified by the appearance of the $\mathrm{m} / \mathrm{z}$ 266 ion in Figure 3, upper panel. Cleavage of the carbon-nitrogen bond (with associated hydrogen atom transfer) at the terminal nitrogen atom of the lysine residue liberates phenylbutenoic acid $\left(M_{r}=162\right)$, explaining the $266^{+}$signal. Two interesting observations regarding this dissociation process are (1) its absence

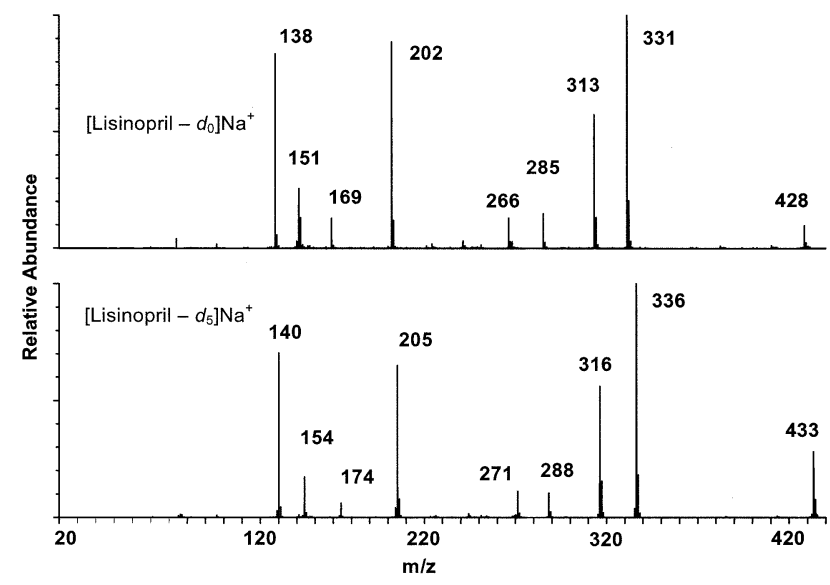

Figure 3. Product ion collision-induced dissociation (CID) MS/MS spectrum for the $\left[\mathrm{M}-d_{0}+\mathrm{Na}\right]^{+}$ion $(\mathrm{m} / z$ 428) (upper panel) and $\left[\mathrm{M}-d_{5}+\mathrm{Na}\right]^{+}(\mathrm{m} / z$ 433) (lower panel) of lisinopril. 
Table 2. Summary of collision-induced dissociation (CID) product ion MS/MS spectra of the $[\mathrm{M}+\mathrm{H}]^{+}$ions for six ACE inhibitor esters. The fragmentation information is categorized and arranged by dissociation processes rather than the typical ascending or descending order of mass-to-charge ratio values. A threshold value of $2 \%$ relative abundance was used in summarizing the CID spectra represented in the table

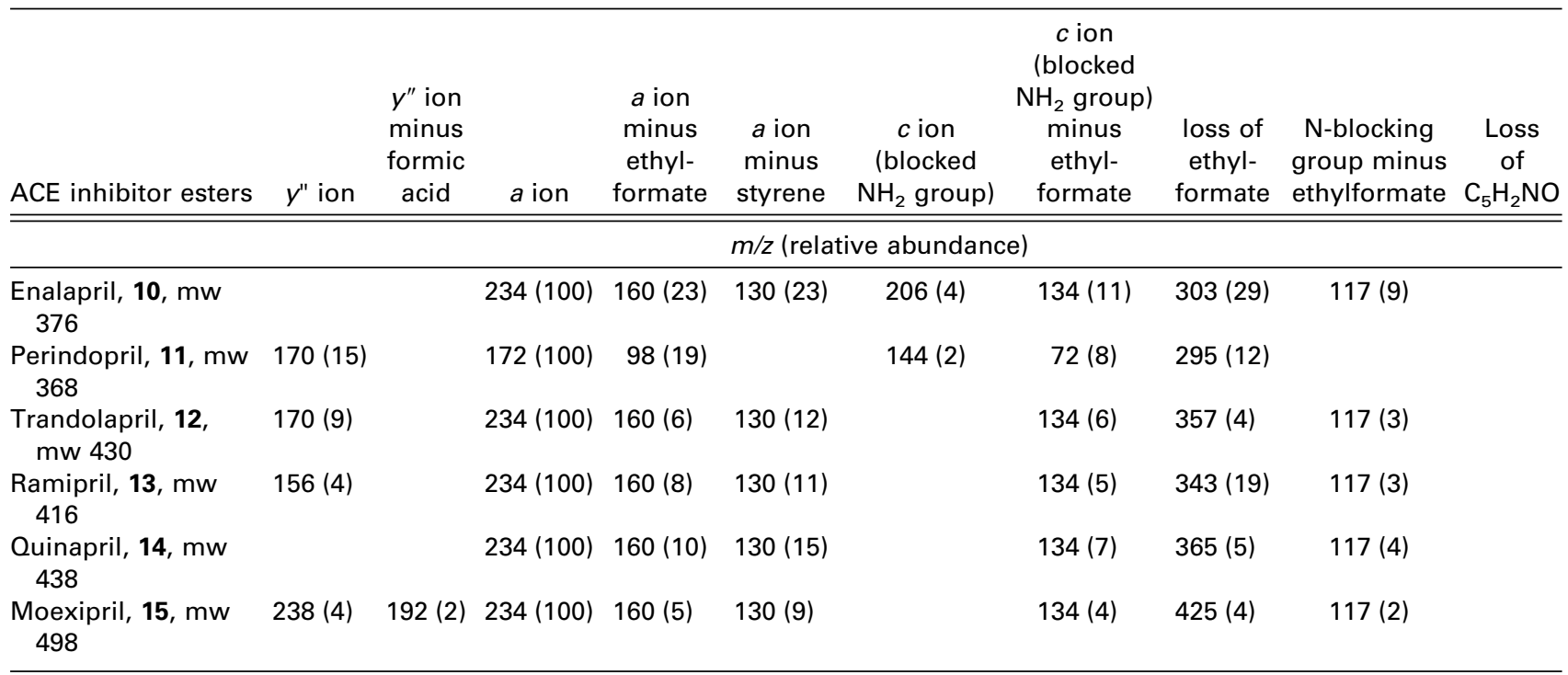

from the spectrum of the protonated lisinopril molecule and (2) it being another example of deuteron mobility during the CID process. The lack of a mass shift for the neutral loss product $\left(\mathrm{M}_{\mathrm{r}}=162\right.$, comparing the spectra in the upper and lower panels of Figure 3) means that the deuteron attached to the carboxylic acid hydroxyl oxygen atom of the phenylbutyric acid undergoes an intramolecular back exchange reaction. Thus, the phenylbutenoic acid molecule liberated from the [lisinopril$\left.d_{5}\right] \mathrm{Na}^{+}$ion contains no deuterons. Differences in the fragmentation behavior of the protonated and sodiated species continued to be evident with the observation of the abundant signal at $\mathrm{m} / \mathrm{z} 202$ in Figure 3, and the absence of a corresponding signal in the upper panel of Figure 2. This fragment ion is the product of bond scission between the $\mathrm{N}$-terminal nitrogen atom and the $\alpha$-carbon of lysine, with retention of charge $\left(\mathrm{Na}^{+}\right)$on the 2-amino-4-phenylbutyric acid. The product ion spectrum of the deuterium-exchanged ion shows retention of three deuterons in the corresponding ion at $\mathrm{m} / \mathrm{z}$ 205 . This result is consistent with the proposed structure and shows no evidence of any unexpected mobility (i.e., unanticipated exchange or back exchange) among the deuterons associated with the two heteroatoms ( $\mathrm{N}$ and O). The next two lower mass ions $(\mathrm{m} / z 169$ and 151) in the product ion spectrum of sodiated lisinopril are most likely the products of sequential dissociation events involving the $\mathrm{m} / \mathrm{z} 266$ ion discussed earlier $\left(428^{+}\right.$ $\rightarrow 266^{+} \rightarrow 169^{+}$and $428^{+} \rightarrow 266^{+} \rightarrow 151^{+}$). Those ions are produced by elimination of $\mathrm{C}_{5} \mathrm{H}_{7} \mathrm{NO}\left(\mathrm{M}_{\mathrm{r}}=97\right)$ and proline $\left(\mathrm{C}_{5} \mathrm{H}_{9} \mathrm{NO}_{2}, \mathrm{M}_{\mathrm{r}}=115\right)$. These assignments are consistent with processes observed for the $[\mathrm{M}+\mathrm{H}]^{+}$of lisinopril, namely those responsible for the formation of the product ions at $\mathrm{m} / \mathrm{z} 309$ and 291 (Figure 2). The most abundant ion in the product ion spectrum of protonated lisinopril $(\mathrm{m} / \mathrm{z} 84)$ has no analogous signal in the product ion spectrum of the sodiated species. The absence of this signal confirms the importance of protonation at the amine nitrogen atom of the lysine side chain as a pivotal step in the formation of not only the $84^{+}$ion, but also the three product ions with $\mathrm{m} / \mathrm{z} 389,360$, and 343 . The conclusion to be drawn from the dissociation behavior induced by the two different charge bearing species (proton vs. sodium cation) is that they attach to the analyte molecule at several locations (competitively). The resulting ion populations of mixed structures can access various competitive fragmentation channels. The data also indicate that the two different ionizing species exhibit varying degrees of mobility after collisional excitation. Both of the deuterated species ([lisinopril- $\left.d_{5}\right] \mathrm{D}^{+}$and [lisinopril- $\left.d_{5}\right] \mathrm{Na}^{+}$) displayed varying degrees of isotopic scrambling, mobility or back exchange, but there are fewer instances of this behavior when charge is imparted by a sodium cation.

Like lisinopril, all but one of the thirteen remaining compounds are N-blocked dipeptides (see Figure 1). The N-terminal blocking group is either ethylphenylbutyrate or phenylbutyric acid in ten of the molecules, and ethylbutyrate or ethylbutyric acid in the other two. Twelve of the compounds possess the amino acid alanine as the N-terminal residue, taking the place of the lysine residue in lisinopril. The high degree of homology in these compounds was reflected in their product ion spectra. However, while these molecules are similar, among twelve of the compounds the Cterminal residue position is occupied by five different amino acids. The positive CID product ion spectra of all fourteen ester and acid ACE inhibitor compounds ([M $+\mathrm{H}]^{+} \rightarrow$ products) are summarized in Tables 2 and 3. Because of the various structural differences that man- 
Table 3. Summary of collision-induced dissociation (CID) product ion MS/MS spectra and the $[\mathrm{M}+\mathrm{H}]^{+}$ions for seven ACE or descending order of mass-to-charge ratio values. A threshold value of $2 \%$ relative abundance was used in summarizing the CID

\begin{tabular}{|c|c|c|c|c|c|c|c|c|}
\hline ACE inhibitor acids & $y^{\prime \prime}$ ion & $\begin{array}{c}y^{\prime \prime} \text { ion } \\
\text { minus } \\
\text { formic acid }\end{array}$ & $a$ ion & $\begin{array}{c}a \text { ion } \\
\text { minus } \\
\text { formic acid }\end{array}$ & $\begin{array}{c}\text { a ion } \\
\text { minus } \\
\text { styrene }\end{array}$ & $\begin{array}{c}b \text { ion } \\
\text { minus } \\
\text { formic acid }\end{array}$ & $\begin{array}{c}c \text { ion } \\
\text { (blocked } \\
\mathrm{NH}_{2} \text { group) }\end{array}$ & $\begin{array}{c}c \text { ion } \\
\text { (blocked } \\
\mathrm{NH}_{2} \text { group) } \\
\text { minus } \\
\text { formic acid }\end{array}$ \\
\hline & & & & & & & \multicolumn{2}{|c|}{$m / z$ (relative abundance } \\
\hline Lisinopril, 1, mw 405 & & & $263(9)$ & & & & & \\
\hline Enalaprilat, 2, mw 348 & & & $206(100)$ & $160(53)$ & $102(32)$ & & $178(6)$ & $134(8)$ \\
\hline Perindoprilat, 4, mw 340 & $170(70)$ & & $144(100)$ & $98(54)$ & & $124(7)$ & $116(14)$ & \\
\hline Trandolaprilat, 5, mw 402 & $170(68)$ & & $206(100)$ & $160(15)$ & $102(15)$ & $124(7)$ & & $134(7)$ \\
\hline Ramiprilate, 6, mw 388 & $156(38)$ & & $206(100)$ & $160(24)$ & $102(15)$ & & & $134(8)$ \\
\hline Quinaprilat, 7, mw 410 & $178(17)$ & $132(4)$ & $206(100)$ & $160(20)$ & $102(14)$ & & & $134(7)$ \\
\hline Moexiprilate, 8, mw 470 & $238(52)$ & $192(9)$ & $206(100)$ & $160(10)$ & $102(9)$ & & & $134(6)$ \\
\hline
\end{tabular}

Note: The distinct dissociation reactions of captopril are discussed in the text.

ifest themselves in different $\mathrm{m} / \mathrm{z}$ values for both protonated molecules and diagnostic product ions, the information contained in these tables is presented according to the types of processes responsible for their formation or appearance rather than being displayed in the conventional fashion of ascending or descending order according to the magnitude of the $\mathrm{m} / \mathrm{z}$ value.

The ACE inhibitor ester CID spectra shown in Table 2 are all dominated (base peak) by the signal representing the $a$ ion. In peptide product ion spectra, this signal is often attributed to $b$ ion formation followed by subsequent loss of carbon monoxide. However, none of the spectra showed any evidence of $b$ ion formation. While the absence of a signal for the intermediate product of a sequential series of dissociation reactions does not necessarily rule out the existence of the twostep process (concerted elimination of proline and carbon monoxide), the lack of any evidence of $b$ ion formation for the six molecules in the data set appears to support direct formation of the $a$ ion (direct cleavage and loss of $\mathrm{N}$-formylproline). Most of these compounds undergo the same six major decomposition reactions. Four of these reaction channels involve the elimination of ethylformate, a major portion of the N-terminus blocking group. A fifth important pathway results in the expulsion of styrene from product ions (largely $a$ ions) that contain the ethylphenylbutyrate N-blocking group. The final significant decomposition mode of the ACE inhibitor esters produces the familiar $y^{\prime \prime}$ ions that provide primary amino acid sequence information for polypeptides and proteins. Taken together these six dissociation processes account for the majority of the remaining signal intensity (aside from the base peak) in the CID spectra of these molecules. This fact is striking in that there is no intrinsically basic site (i.e., site of charge localization) in the N-terminal blocking group(s) that would serve as the focal point for charge induced (directed) fragmentation. Therefore, these processes are either charge-remote in nature or there is the same type and degree of proton mobility that was evident in the lisinopril results. The other notable feature shared by the six CID spectra summarized in Table 2 is the absence of the rearrangement/elimination process responsible for the formation of the interesting $\mathrm{m} / \mathrm{z} 309$ ion (loss of $\mathrm{C}_{5} \mathrm{H}_{7} \mathrm{NO}$ ) in the lisinopril product ion spectrum.

The six acid ACE inhibitors (summarized in Table 3) show fragmentation behavior very similar to that of their ester analogs. The base peak in all of these CID spectra is attributable to the $a$ ion. For the five compounds containing the phenylbutyric acid N-terminus blocking group, this ion is $m / z 206$, while for the remaining member of the group (perindoprilat, with butyric acid as the blocking group) the ion is $m / z 144$. Of the other dissociation processes exhibited by the acid compounds, the loss of formic acid (analogous to the elimination of ethylformate) is prevalent, participating in four of the six remaining significant decomposition channels. The other two processes that merit mention are the loss of styrene and the formation of $y^{\prime \prime}$ ions. Once again, it is clear that most of the product ions are originating from that portion of the molecules originally comprising the N-terminal blocking group of the dipeptide structure. As mentioned in the discussion of the dissociation behavior of the esters (vide supra), the expulsion of formic acid (like that of ethylformate from the ester compounds) must either be charge remote in nature, or dependent upon mobile protons. Strikingly, the rearrangement/elimination process responsible for the formation of the interesting $\mathrm{m} / \mathrm{z} 309$ ion (loss of $\mathrm{C}_{5} \mathrm{H}_{7} \mathrm{NO}$ ) in the lisinopril product ion spectrum is absent from the CID spectra of all the other compounds. Obviously, the structure of the C-terminal amino acid residue has no bearing on the functional group transfer that facilitates loss of that residue. Given the high degree of similarity among the other structural elements of the various molecules, it seems clear that the presence of the primary amine group in the side chain of the N-terminal residue (i.e., lysine vs. alanine) was the pivotal factor responsible for the interesting fragmentation behavior of lisinopril. If protonation at the amide group [23] were responsible for initiating the 
inhibitor acids. The fragmentation information is categorized and arranged by dissociation processes rather than the typical ascending spectra represented in the table

\begin{tabular}{|c|c|c|c|c|c|c|c|}
\hline $\begin{array}{c}\text { loss of } \\
\text { formic acid }\end{array}$ & $\begin{array}{l}\text { N- blocking } \\
\text { group } \\
\text { minus } \\
\text { formic acid }\end{array}$ & $\begin{array}{l}\text { loss of } \\
\mathrm{C}_{5} \mathrm{H}_{7} \mathrm{NO}\end{array}$ & loss of $\mathrm{NH}_{3}$ & $\begin{array}{c}\text { loss of } \mathrm{NH}_{3} \\
\text { and formic } \\
\text { acid }\end{array}$ & $\begin{array}{c}a \text { ion minus } \\
\mathrm{NH}_{3}\end{array}$ & $\begin{array}{l}a \text { ion minus } \\
\text { ammonia } \\
\text { and formic } \\
\text { acid }\end{array}$ & $\begin{array}{l}a \text { ion minus } \\
\text { ammonia } \\
\text { and phenyl } \\
\text { propenoic } \\
\text { acid }\end{array}$ \\
\hline $360(6)$ & & $309(18)$ & $389(2)$ & $343(8)$ & $248(73)$ & $200(6)$ & $84(100)$ \\
\hline $303(30)$ & $117(13)$ & & & & & & \\
\hline 295 (17) & & & & & & & \\
\hline $357(5)$ & $117(7)$ & & & & & & \\
\hline $343(20)$ & $117(8)$ & & & & & & \\
\hline $365(5)$ & $117(8)$ & & & & & & \\
\hline $425(2)$ & $117(5)$ & & & & & & \\
\hline
\end{tabular}

hydroxyl group transfer (and associated loss of $\mathrm{C}_{5} \mathrm{H}_{7} \mathrm{NO}$ ) proposed in the previous lisinopril study, this mechanism should be operative for all of the analogs shown in Tables 2 and 3, and yet this is clearly not the case. It has been suggested that the requisite amideprotonated structure is arrived at after initial protonation of the lysine amine group and some subsequent "interaction" or "sharing/transfer" of the ionizing proton. Such an interaction requires an unusual ninecentered transition state geometry and an endothermic proton transfer, due to the considerable proton affinity differences between primary amines and amides. Both of these requirements seem improbable. If instead, the elimination of $\mathrm{C}_{5} \mathrm{H}_{7} \mathrm{NO}$ from lisinopril was dependent upon the transfer of the proline carboxylic acid group to the N-terminal nitrogen atom of lysine (as proposed in the alternative mechanism shown in Scheme 1), that nitrogen atom must not bear the ionizing proton. If that nitrogen atom were the site of protonation, the resulting positive charge would prevent electrophilic attack of the carboxylic acid group carbonyl carbon atom and therefore prevent the rearrangement. Alternatively, when protonation occurs primarily or preferentially at the side chain amino group, the lysine N-terminal nitrogen atom retains its basic character and its ability to serve as a receptor for the carboxylic acid functional group that must be transferred in order to enable the elimination reaction.

Captopril, 3 (the first member of the ACE inhibitor therapeutic class) constitutes a special case, possessing a very simple structure that includes the acyl proline moiety that is common to several members of the class, but not the second amino acid residue. The simple and distinct nature of its structure (branched alkyl thiol) is reflected in the CID product ion spectrum of the protonated molecule. The fragmentation processes are dominated by the elimination of $\mathrm{N}$-formylproline ([M + $\left.\mathrm{H}-\mathrm{R}_{1} \mathrm{CHO}\right]^{+}, m / z$ 75) with charge retention on the alkyl thiol side chain. Proline also figures prominently in the formation of product ions at $m / z 70,103$, and 116, either through its elimination $(m / z 103)$, it's elimination with subsequent loss of formic acid $(\mathrm{m} / \mathrm{z} 70)$ or retention of charge to yield $m / z 116$. The elimination of formic acid from the protonated molecule is also likely to be the source of the ion at $m / z 172$, although loss of thioformaldehyde would also fit for that nominal mass. The low $m / z$ value region of the spectrum exhibits signals for protonated thioformaldehyde $(\mathrm{m} / \mathrm{z} 47)$ and

Table 4. Summary of collision-induced dissociation (CID) product ion MS/MS spectra of the $[\mathrm{M}-\mathrm{H}]^{-}$ions for eight ACE inhibitor acids. The fragmentation information is categorized and arranged by dissociation processes rather than the typical ascending or descending order of mass-to-charge ratio values. A threshold value of $5 \%$ relative abundance was used in summarizing the CID spectra represented in the table

\begin{tabular}{lccc}
\hline ACE inhibitor acids & $y$ ion & $\begin{array}{c}\text { loss of } \mathrm{CO}_{2} \\
\text { and thio- } \\
\text { formaldehyde }\end{array}$ & $\begin{array}{c}\text { loss of } \\
\text { hydrogen } \\
\text { sulfide }\end{array}$ \\
\hline \hline Lisinopril, 1, mw 405 & $114(100)$ & $\mathrm{m} / \mathrm{z}$ (relative abundance) & \\
Enalaprilat, 2, mw 348 & $114(100)$ & & \\
Captopril, 3, mw 217 & $114(100)$ & & \\
Perindoprilat, 4, mw 340 & $168(100)$ & & \\
Trandolaprilat, 5, mw 402 & $168(100)$ & & \\
Ramiprilat, 6, mw 388 & $154(100)$ & & \\
Quinaprilat, 7, mw 410 & $176(100)$ & & \\
Moexiprilat, 8, mw 470 & $236(100)$ & & \\
\hline
\end{tabular}


the propenyl cation $\left(\mathrm{C}_{3} \mathrm{H}_{5}^{+}\right)$. The absence of a favorable receptor site and the inability to form a favorable fiveor six-centered transition state geometry explains why no $\mathrm{C}_{5} \mathrm{H}_{7} \mathrm{NO}$ is eliminated from captopril.

\section{Negative Ion Study}

Negative ion detection is employed to enhance sensitivity and selectivity of mass spectral analyses. While not as widely used as positive ion detection, due to the smaller number of compounds that form stable anions, negative ion detection can be particularly useful for specific compound classes (e.g., carboxylic acids). In addition to their analytical utility, the unimolecular dissociation chemistry of negative ions can also be unique and interesting. The site of charge localization (most commonly as a consequence of deprotonation, although radical anions are favored for particular classes of molecules) in anions is generally quite different from the site of protonation. Consequently, the fragmentation pathways observed for anions can provide complimentary structural information of either analytical or fundamental interest.

The CID product ion spectra obtained for the anions $\left([\mathrm{M}-\mathrm{H}]^{-}\right)$of the eight acid ACE inhibitors were strikingly simple in their appearance (Table 4). Under the same experimental conditions that produced a series of structurally informative product ions for the protonated acid molecules, the anions of all the compounds but captopril yielded spectra exhibiting only a single signal-the deprotonated C-terminus amino acid residue. This observation is interesting for a number of reasons. Localization of charge at the C-terminal carboxylate group indicates that scission of the amide bond is not charge directed, with bond cleavage and associated hydrogen transfer occurring some distance from the site of deprotonation. Also, the presence of two carboxylic acid groups in these molecules raises the possibility of competitive sites of deprotonation (ionization). Each of the acid functional groups is located $\beta$ to a nitrogen atom, one an amide nitrogen atom and the other a secondary amine nitrogen atom. The impact of these two chemically distinct nitrogen atoms on the relative acidity of the two $-\mathrm{COOH}$ groups is clear. Deprotonation of the C-terminal acid group appears to dominate, as reflected by the absence of any dissociation channels attributable to deprotonation of the Nterminus blocking group carboxylic acid. The appearance of only the $y$ ion in the fragmentation spectra of these compounds limits the utility of negative ion mode investigations from a structure elucidation perspective. However, the specificity of molecular anion formation for the carboxylic acid compounds coupled with the limited number of dissociation channels makes for an ideal scenario for detecting and quantifying these compounds using selected reaction monitoring protocols, such as those commonly employed in metabolism studies $[15,16]$. Although it is relatively small in size and simple in structure compared with the other com- pounds studied, the captopril molecular anion appears to stabilize charge more effectively than those of the other acids as indicated by its appearance in the product ion CID spectrum. The captopril CID spectrum contains two signals in addition to the $y$ ion-elimination of hydrogen sulfide $(\mathrm{m} / \mathrm{z}$ 182) and consecutive (or concerted) losses of thioformaldehyde and carbon dioxide $\left(m / z\right.$ 126). The loss of $\mathrm{CO}_{2}$ from carboxylate anions is an expected process, being both charge directed and resulting in the elimination of a very stable, small neutral molecule. Despite the high degree of similarity between the acid ACE inhibitors, it is somewhat unexpected that none of the other molecules in the class exhibit this unimolecular dissociation process.

Unlike the acid ACE inhibitors, the anions ([M $\mathrm{H}]^{-}$) of the six esters produced CID product ion spectra that were information rich, containing numerous signals. The spectra are summarized in Table 5 and show not only a significant number of fragmentation channels, but also considerable diversity among the dissociation products. Among all of the types of ions examined in this study under reasonably constant CID experimental conditions (i.e., consistency in collision energies and target gas pressures), the molecular anions of the esters show the greatest stability toward fragmentation. The ester compounds exhibited relative abundances for the $[\mathrm{M}-\mathrm{H}]^{-}$ions that ranged from $15-100 \%$. The major point of consistency between the CID spectra of the ester and acid anions was the prominence of the signals representing the $y$ ion. All six of the ester compounds exhibited robust signals for the carboxylate anion of the C-terminal amino acid residue, ranging from 52-100\% relative abundance. The only other dissociation process that was common to all of the compounds was the formation of what is described as the $z$-ion $\left(\mathrm{RCH}_{2} \mathrm{CO}_{2}^{-}\right.$, with fragmentation occurring between the $\alpha$-carbon and the N-terminal nitrogen atom of the Ala residue), which has undergone subsequent elimination of $\mathrm{CO}_{2}$. The next most prevalent signal (displayed in the CID spectra of four of the compounds) is the result of two sequential (or concerted) dissociation processes involving the $\mathrm{C}$-terminal residue and the $\mathrm{N}$-terminal blocking group. This combined loss of the C-terminal residue as the neutral amino acid and the ester portion of the blocking group as ethylformate results in the appearance of a $m / z 186$ signal in the product ion CID spectra for the anions of Compounds 10, 13-15. The elimination of the C-terminal residue as the neutral amino acid requires the transfer of two hydrogen atoms and localization of the negative charge in a portion of the molecule that does not appear particularly well suited to stabilize it. While this unimolecular dissociation process would be more easily accommodated by a precursor ion structure having the charge localized initially at a site other than the carboxylate group (e.g., loss of a proton that is $\alpha$ to a carbonyl group or deprotonation of the secondary amine), the formation of such an ion during the ESI process would be unusual. It seems far more probable that charge migration occurs 
upon collisional activation through the movement of one or more mobile protons. Upon initial inspection, the elimination of ethylformate from the N-terminus blocking group (either ethylpentanoate or ethylphenylbutyrate) would seem to be charge remote in its origin. However, a charge directed process can be envisioned through deprotonation not at the carboxylate hydroxyl oxygen but rather at the carbon atom $\alpha$ to the ester carbonyl carbon atom (i.e., enolate anion formation) or deprotonation of the adjacent secondary amine. The formation of enolate anions from esters is not uncommon under classical chemical ionization conditions [25], but requires strongly basic reagent ions, since the acidity of the protons positioned $\alpha$ with respect to the ester carbonyl group is low (i.e., differs by several orders of magnitude) in comparison to that of carboxylic acids. Thus, formation of such an enolate under normal electrospray ionization conditions is not favored. Similarly, the relative acidities $\left(\mathrm{pK}_{\mathrm{a}}\right)$ of the proline carboxylic acid group and the blocked terminal amine group of alanine differ by many orders of magnitude in favor of the carboxylic acid. Consequently, the elimination of the ethylformate may be charge directed, but only after the requisite proton transfer reactions, since initial deprotonation of the secondary amine seems unlikely. The elimination of ethylformate also figures prominently in six additional fragmentation processes described in Table 5. The combined elimination of ethylformate and carbon dioxide produces signals in the CID spectra of Compounds 10, 11, 14, and 15, while only two of the compounds exhibit signals for the ethylformate loss alone. None of the compounds show a loss of either the neutral C-terminal residue or $\mathrm{CO}_{2}$ without the accompanying ethylformate loss. Inexplicably trandolapril, $\mathbf{1 2}$, exhibits none of these dissociation processes despite its high degree of structural homology with Compounds $\mathbf{1 1}$ and $\mathbf{1 3}$.

The remainder of the ion current in the fragmentation spectra of the six ester anions summarized in Table 5 is distributed among more than a dozen reaction channels that show little similarity or consistency among the various compounds, despite their structural similarities. Many of these decomposition reactions appear in the spectrum of only a single member of the series of compounds, and most produce ions having low to moderate abundances. Some of these signals are indicative of the structural diversity in the C-terminal residue, such as the loss of formaldehyde molecules from the dimethoxy substituted quinoline of moexipril. Other signals appear to represent radical anions and their intensities indicate considerable stability for those structures. The complexity of the CID spectra of the ester anions is somewhat remarkable when compared to the very simple spectra obtained for the ester cations or the diacid anions. Some of the uncommon, unfamiliar and interesting dissociation channels (including possible rearrangements) that are accessed by the activated/decomposing ACE ester anions will require further study and investigation.

\section{Conclusions}

The ACE inhibitors constitute an important class of therapeutic molecules that display interesting unimolecular chemistry upon low energy collisional activation. A specific rearrangement mechanism observed for one of the members of this class (lisinopril) has been explored in detail through the use of product ion CID spectra, deuterium exchange, sequential dissociation reactions $\left(\mathrm{MS}^{3}\right)$ and exact $m / z$ measurements. Despite a high degree of similarity among the related compound structures examined in this study, only lisinopril displayed the unusual rearrangement. Several additional decomposition channels of protonated lisinopril (i.e., formation of $\mathrm{m} / \mathrm{z} 246$ and its subsequent dissociation products) were also examined using exact $m / z$ measurements and found to differ from a proposal put forth by the authors of a previous study. The significant impact of the side-chain amino group of the lysine residue on the unimolecular dissociation chemistry was evident from the CID processes exhibited both by protonated $\left([\mathrm{M}+\mathrm{H}]^{+}\right)$and sodiated $\left([\mathrm{M}+\mathrm{Na}]^{+}\right)$lisinopril. Substitution of the charge carrying proton with sodium had no effect on some of the decomposition reactions, producing analogous product ions (differing only in the mass of the charge carrier). In other instances however, the absence of the ionizing proton completely eliminates certain dissociation pathways. Most notable among these suppressed fragmentation cascades are those initiated by the elimination of ammonia-due either to differences in the site of attachment, relative binding strengths or mobilities for the two different ionizing particles.

The previously unreported CID product ion spectra of the anions $\left([\mathrm{M}-\mathrm{H}]^{-}\right)$of the ACE inhibitors, exhibited a number of interesting attributes. The seven diacid molecules, 1, 2, 4-8 (i.e., those compounds possessing carboxylic acid functional groups at both the C-terminus and in the N-terminus blocking group) displayed surprisingly simple spectra that showed only a single signal, the deprotonated $\mathrm{C}$-terminal amino acid residue ( $y$ ion). These spectra have limited utility from the perspective of structure elucidation, but are ideal for analytical applications that employ selected reaction monitoring (SRM). The six ACE inhibitor ester molecules, 9-14, yielded unexpectedly complex dissociation spectra, displaying numerous decomposition channels not observed for the corresponding diacids. They reflect a scenario where no one decomposition channel dominates. Like the diacids, the deprotonated ACE esters yield abundant $y$ ions. These ions are indicative of formation and retention of charge (deprotonation of the carboxylic acid) at the most probable site in the molecule. They provide a rapid means of confirming the identity of the analyte in question, since much of the homology in this compound class is present in the structure of the C-terminal amino acid. The only other signals common to the CID spectra of all six of these compounds represent the decarboxylated $z$ ion $(z$-ion 


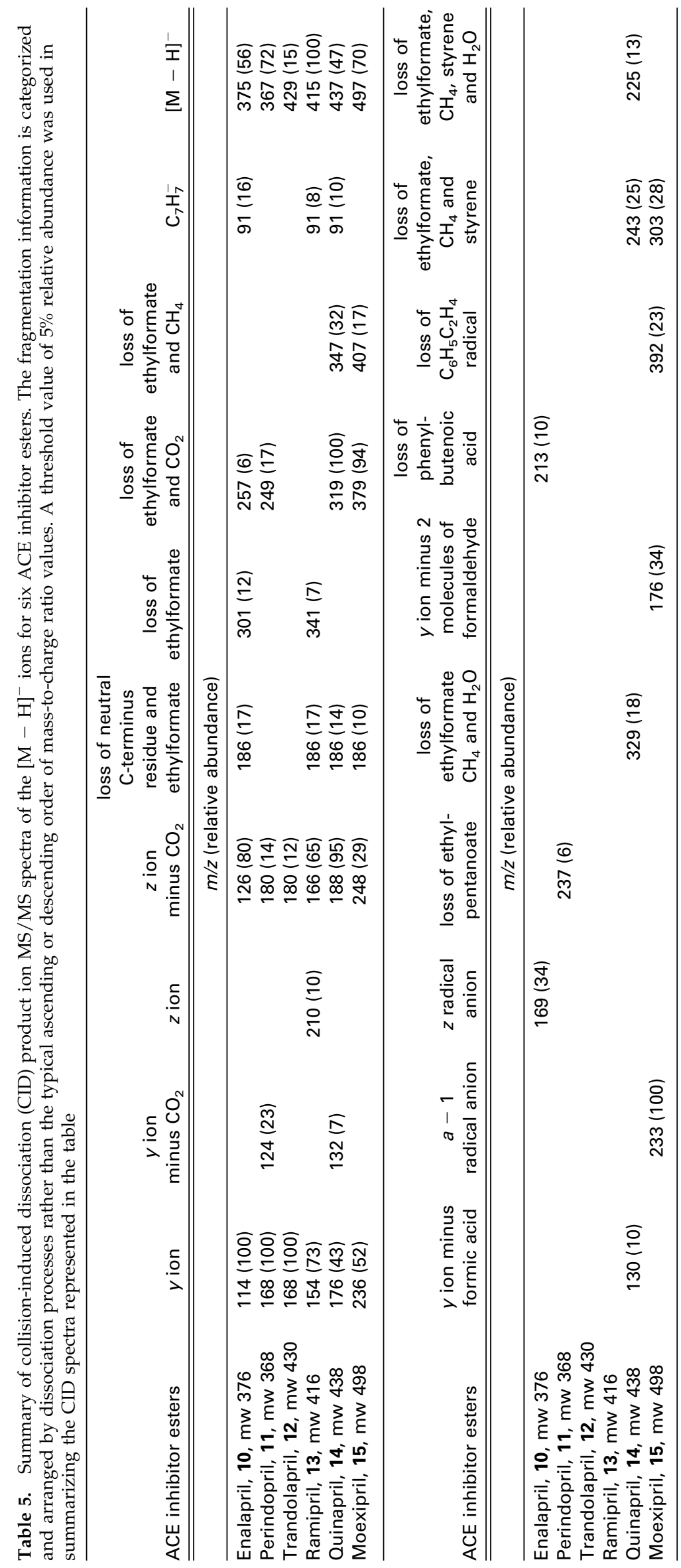


minus $\mathrm{CO}_{2}$ ) and the intact deprotonated molecule ([M $-\mathrm{H}]^{-}$). The lack of commonality or consistency among the remaining signals summarized in Table 5 was unexpected and requires additional study.

\section{Acknowledgments}

The authors acknowledge Dr. Kevin Facchine for his support of this work.

\section{References}

1. Douglas, W. W. Polypeptides-Angiotensin, Plasma Kinins, and Others. In The Pharmacological Basis of Therapeutics, 7th ed.; Gilman, A. G.; Goodman, L. S.; Rall, T. W.; Murad, F., Eds.; Macmillan: New York, 1985; Chap XXVII, pp 639-659.

2. Natesh, R.; Schwager, S. L. U.; Sturrock, E. D.; Acharya, K. R. Crystal Structure of the Human Angiotensin-Converting Enzyme-Lisinopril Complex. Nature 2003, 421, 551-554.

3. Cushman, D. W.; Chenng, H. S.; Sabo, E. F.; Ondetti, M. A. Design of Potent Competitive Inhibitors of Angiotensin-Converting Enzyme. Carboxyalkanoyl and Mercaptoalkanoyl Amino Acids. Biochemistry 1977, 16, 5484-5491.

4. Ondetti, M. A.; Rubin, B.; Cushman, D. W. Design of Specific Inhibitors of a New Class of Orally Active Antihypertensive Agents. Science 1977, 196, 441-444.

5. Andrews, P. R.; Carson, J. M.; Casseli, A.; Spark, M. J.; Woods, R. Conformational Analysis and Active Site Modeling of Angiotensin-Converting Enzyme Inhibitors. J. Med. Chem. 1985, 28, 393-399.

6. Thorsett, E. D.; Harris, E.; Aster, S.; Peterson, E. R.; Snyder, J. P.; Hirshfield, J.; Tristram, E. W.; Patchett, A. A.; Ulm, E. H.; Vassil, T. C. Conformationally Restricted Inhibitors of Angiotensin Converting Enzyme: Synthesis and Computations. J. Med. Chem. 1986, 29, 251-260.

7. Laffan, R. J.; Goldberg, M. E.; High, J. P.; Schaeffer, R. R.; Waugh, M. H.; Rubin, B. Antihypertensive Activity in Rats of SQ 14225, an Orally Active Inhibitor of Angiotensin Converting Enzyme. J. Pharmocol. Exp. Ther. 1987, 204, 281-288.

8. Qin, X. Z.; Wang, Q.; Visentini, J.; Kwong, E. Detection and Identification of an Enalaprilat Isomer in Enalapril Formulations. J. Isol. Purif. 1997, 2, 275-288.

9. Sioufi, A.; Pommier, F.; Kaiser, G.; Dubois, J. P. Determination of Benazepril, a New Angiotensin-Converting Enzyme Inhibitor and Its Active Metabolite, Benazeprilat, in Plasma and Urine by Capillary Gas Chromatography Mass-Selective Detection. J. Chromatogr. 1988, 434, 239-246.

10. Tsaconas, C.; Devissaguet, M.; Padieu, P. Gas Chromatography Mass Spectrometry of Perindopril and Its Active Free Metabolite, an Angiotensin Convertase Inhibitor: Choice of Derivatives and Ionization Modes. J. Chromatogr. 1989, 488, 249-265.

11. Waldmeier, F.; Kaiser, G.; Ackermann, R.; Faigle, J. W.; Wagner, J.; Barner, A.; Lasseter, K. C. The Disposition of $\left[{ }^{14} \mathrm{C}\right]-$ Labeled Benazepril Hydrochloride in Normal Adult Volunteers After Single and Repeated Oral Dose. Xenobiotica 1991, 21, 251-261.

12. Goto, N.; Kamata, T.; Ikegami, K. Trace Analysis of Quinapril and Its Active Metabolite, Quinaprilat, in Human Plasma and
Urine by Gas Chromatography Negative-Ion Chemical Ionization Mass Spectrometry. J. Chromatogr. 1992, 578, 195-201.

13. Lies, H. J.; Gleipach, H.; Windischhofer, W. Stable Isotope Labeling and Quantitative Determination of Enalaprilat in Human Plasma by GC-NICI-MS. J. Mass Spectrom. 1995, 30, 1447-1452.

14. Franklin, M. E.; Addison, R. S.; Baker, P. V.; Hooper, W. D. Improved Analytical Procedure for the Measurement of Captopril in Human Plasma by Gas Chromatography Mass Spectrometry and Its Application to Pharmacokinetic Studies. J. Chromatogr. B 1998, 705, 47-54.

15. Dal Bo, L.; Mazzucchelli, P.; Marzo, A. Assay of Zofenopril and Its Active Metabolite Zofenoprilat by Liquid Chromatography Coupled with Tandem Mass Spectrometry. J. Chromatogr. B 2000, 749, 287-294.

16. Zhu, Z.; Vachareau, A.; Neirinck, L. Liquid Chromatography Mass Spectrometry Method for Determination of Ramipril and Its Active Metabolite Ramiprilat in Human Plasma. J. Chromatogr. B 2002, 779, 297-306.

17. Fernandez, M. T.; Silva, M. M.; Mira, L.; Florêncio, M. H.; Gill, A.; Jennings, K. R. Iron and Copper Complexation by Angiotensin-Converting Enzyme Inhibitors. A Study by Ultraviolet Spectroscopy and Electrospray Mass Spectrometry. J. Inorg. Biochem. 1998, 71, 93-98.

18. Silva, C. M. L.; Duarte, M. F.; Mira, M. L.; Florêncio, M. H.; Versluis, K.; Heck, A. J. R. Copper and Iron Interactions with Angiotensin-Converting Enzyme Inhibitors. A Study by FastAtom Bombardment Tandem Mass Spectrometry. Rapid Commun. Mass Spectrom. 1999, 13, 1098-1103.

19. Florêncio, M. H.; Fernandez, M. T.; Mira, M. L.; Millar, A.; Jennings, K. R. Electrospray Mass Spectrometry of Angiotensin-Converting Enzyme Inhibitors. Rapid Commun. Mass Spectrom. 1998, 12, 1928-1932.

20. Cartoni, A.; Altamura, M.; Animati, F.; Balacco, G.; Cosi, R.; Ettorre, A.; Madami, A.; Triolo, A. An Unusual Rearrangement of Zofenopril, a New ACE Inhibitor Drug: Mass Spectrometric and Conformational Studies. J. Mass Spectrom. 2002, $37,1258-1265$.

21. Tyler, A.; Clayton, E.; Green, B. Exact Mass Measurement of Polar Organic Molecules at Low Resolution Using Electrospray Ionization and a Quadrupole Mass Spectrometer. Anal. Chem. 1996, 68, 3561-3569.

22. Olsen, M. A.; Cummings, P. G.; Kennedy-Gabb, S.; Wagner, B. M.; Nicol, G. R.; Munson, B. The Use of Deuterium Oxide as a Mobile Phase for Structural Elucidation by HPLC/UV/ESI/ MS. Anal. Chem. 2000, 72, 5070-5078.

23. Wysocki, V. H.; Tsaprailis, G.; Smith, L. L.; Breci, L. A. Mobile and Localized Protons: A Framework for Understanding Peptide Dissociation. J. Mass Spectrom. 2000, 35, 1399-1406.

24. Roepstorff, P.; Fohlman, J. Proposal for a Common Nomenclature for Sequence Ions in Mass Spectra of Ppeptides. Biomed. Mass Spectrom. 1984, 11, 601.

25. Bowie, J. H.; Stringer, M. B.; Hayes, R. N.; Raftery, M. J.; Currie, G. J.; Eichinger, P. C. H. Collision Induced Dissociations of Enolate Negative Ions in the Gas Phase. Spectroscopy 1985, 4, 277-296.

26. Louris, J. N.; Cooks, R. G.; Syka, J. E. P.; Kelley, P. E.; Stafford, G. C.; Todd, J. F. J. Instrumentation, Applications, and Energy Deposition in Quadrupole Ion-Trap Mass Spectrometry. Anal. Chem. 1987, 59, 1677-1685. 